\title{
Mesenchymal stem cells alleviate experimental autoimmune cholangitis through immunosuppression and cytoprotective function mediated by galectin-9
}

Junyu Fan ${ }^{1 \dagger}$, Xiaojun Tang ${ }^{2 \dagger}$, Qian Wang ${ }^{2}$, Zhuoya Zhang ${ }^{2}$, Shufang Wu'², Wenchao Li ${ }^{2}$, Shanshan Liu ${ }^{2}$, Genhong $\mathrm{YaO}^{2}$, Hongwei Chen ${ }^{2^{*}}$ and Lingyun Sun ${ }^{1,2^{*}}$ (D)

\begin{abstract}
Background: Mesenchymal stem cells (MSCs) play an anti-inflammatory role by secreting certain bioactive molecules to exert their therapeutic effects for disease treatment. However, the underlying mechanism of MSCs in chronic autoimmune liver diseases_- primary biliary cholangitis (PBC), for example_-remains to be elucidated.

Methods: Human umbilical cord-derived MSCS (UC-MSCS) were injected intravenously into 2-octynoic acid coupled to bovine serum albumin (2OA-BSA)-induced autoimmune cholangitis mice. Serum levels of biomarkers and autoantibodies, histologic changes in the liver, diverse $C D 4^{+} \mathrm{T}$-cell subsets in different tissues, and chemokine activities were analyzed. Moreover, we investigated galectin-9 (Gal-9) expression and its function in UC-MSCs.
\end{abstract}

Results: In this study, UC-MSC transplantation (UC-MSCT) significantly ameliorated liver inflammation, primarily by diminishing Thelper 1 (Th1) and Th17 responses as well as modifying liver chemokine activities in experimental autoimmune cholangitis mice. Mechanistically, UC-MSCs significantly repressed the proliferation of CD4 ${ }^{+} \mathrm{T}$ cells and suppressed the differentiation of Th1 and Th17 cells, which was likely dependent on Gal-9. Furthermore, the signal transducer and activator of transcription (STAT) and c-Jun N-terminal kinase (JNK) signaling pathways were involved in the production of Gal-9 in UC-MSCs.

Conclusions: These results suggest that Gal-9 contributes significantly to UC-MSC-mediated therapeutic effects and improve our understanding of the immunomodulatory mechanisms of MSCs in the treatment of PBC.

Keywords: Umbilical cord-derived mesenchymal stem cells, Primary biliary cholangitis, Galectin-9, Inflammation

\section{Background}

Primary biliary cholangitis $(\mathrm{PBC})$ is a chronic cholestatic autoimmune liver disease, characterized by slow progressive destruction of small and medium-size intrahepatic bile ducts, which when untreated will culminate in

\footnotetext{
* Correspondence: chenhw02@hotmail.com; lingyunsun@nju.edu.cn

†Junyu Fan and Xiaojun Tang contributed equally to this work.

2Department of Rheumatology and Immunology, The Affiliated Drum Tower Hospital of Nanjing University Medical School, 321 Zhongshan Road, Nanjing 210008, China

${ }^{1}$ Nanjing Drum Tower Hospital, Clinical College of Traditional Chinese and Western Medicine, Nanjing University of Chinese Medicine, Nanjing 210008, China
}

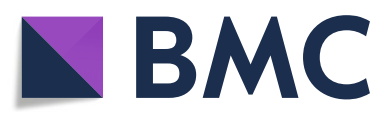

(๑) The Author(s). 2018 Open Access This article is distributed under the terms of the Creative Commons Attribution 4.0 International License (http://creativecommons.org/licenses/by/4.0/), which permits unrestricted use, distribution, and reproduction in any medium, provided you give appropriate credit to the original author(s) and the source, provide a link to the Creative Commons license, and indicate if changes were made. The Creative Commons Public Domain Dedication waiver (http://creativecommons.org/publicdomain/zero/1.0/) applies to the data made available in this article, unless otherwise stated. end-stage biliary cirrhosis [1]. Various cell populations and cytokines are involved in PBC development, indicating a complex mechanism responsible for the pathogenesis of PBC $[2,3]$. Currently, ursodeoxycholic acid (UDCA) and obeticholic acid (OCA) are approved by the US Food and Drug Administration to treat $\mathrm{PBC}$ with demonstrated clinical benefits [4-6]. However, about $25 \%$ to $40 \%$ of patients with $\mathrm{PBC}$ did not achieve a complete treatment response $[7,8]$. Thus, it is necessary to explore new therapies for $\mathrm{PBC}$.

Mesenchymal stem cells (MSCs) can be isolated from various tissues, including bone marrow, umbilical cord 
(UC), and adipose tissues [9]. Capable of differentiating into mesodermal cell lineages, MSCs also have a wide range of immunomodulatory properties [10]. In our previous studies, MSC transplantation (MSCT) showed therapeutic effects on various autoimmune diseases, including systemic lupus erythematosus [11, 12], primary Sjögren's syndrome [13], and rheumatoid arthritis [14, 15]. In 2011, our early experiment in mice raised the possibility of applying syngeneic MSCs to treat PBC [16]. Subsequently, two other clinical trials reported that MSCT was feasible and well tolerated, thus providing an important clue for the treatment of patients with refractory $\mathrm{PBC}$ in the near future $[17,18]$. However, very little is known regarding the underlying mechanism of the therapeutic effects of MSCT in PBC.

Currently, the mechanisms underlying the anti-inflammatory effects of MSCs are being investigated to establish the basis for the effective clinical application of MSCs. MSCs can express a high level of therapeutic factors to exert enhanced immunosuppressive function after interacting with a disease-specific environment [19-21]. Even when MSCs do not migrate directly to inflammation sites or injured tissues, they can still exert anti-inflammatory actions through secretory factors [22-25], such as galectins. Galectins are a group of galactoside-binding lectins that regulate various biological processes. Among these mammalian members, galectin-9 (Gal-9) is a $36-\mathrm{kDa}$ tandem-repeat galectin [26, 27]. Treatment with recombinant Gal-9 ameliorates disease activity in various preclinical models of autoimmunity and allograft graft rejection [28-30]. However, whether UC-MSCs can produce Gal-9 to play an immunoregulatory role is not clear.

The aim of this study was to assess the efficacy of UC-MSCT in 2-octynoic acid coupled to bovine serum albumin (2OA-BSA)-induced murine autoimmune cholangitis and explore its underlying mechanisms. Here, we found that UC-MSC suppressed aberrant Th1 and Th17 responses via Gal-9 and repressed systemic and local inflammation in this $\mathrm{PBC}$ mouse model. Our results suggest that UC-MSCT may serve as an excellent therapeutic strategy for treating PBC.

\section{Methods}

\section{Mice}

Female C57BL/6 mice (6-8 weeks old) were obtained from the Laboratory Animal Center of the Affiliated Drum Tower Hospital of Nanjing University Medical School (Nanjing, Jiangsu, China). Mice were housed in a temperature-controlled environment with a $12 \mathrm{~h}$ lightdark cycle and were given standard laboratory chow and water ad libitum. All animal experiments were performed in accordance with the institutionally approved protocol for the use of animal research.

\section{Isolation of UC-MSC and cell culture}

Fresh human UCs were obtained from the Affiliated Drum Tower Hospital of Nanjing University Medical School. UC-MSCs were prepared as described previously [31]. This study was approved by the ethics committee of the Affiliated Drum Tower Hospital of Nanjing University Medical School. To co-culture UC-MSCs with human biliary epithelial cells (BECs) (Jennio Biotech, Guangzhou, Guangdong, China), confluent BECs were added to the lower transwell chamber in 12-well plates treated with RPMI 1640 medium (Gibco, Life Technologies, Grand Island, NY, USA) supplemented with $10 \%$ fetal bovine serum (FBS) and $100 \mathrm{U} / \mathrm{mL}$ penicillin/streptomycin solution. Then UC-MSCs were seeded into the upper transwell chambers (Corning, New York, NY, USA) for $48 \mathrm{~h}$. Interferon-gamma (IFN- $\gamma)(20 \mathrm{ng} / \mathrm{mL}$, PeproTech, Rocky Hill, NJ, USA) and $\alpha$-lactose $(10.8 \mathrm{mg} / \mathrm{mL}$, Sigma-Aldrich, St. Louis, MO, USA) were added for the treatment of BECs before RNA extraction. All cells were maintained in an atmosphere with 95\% humidity and 5\% carbon dioxide at $37^{\circ} \mathrm{C}$.

\section{Induction of cholangitis and UC-MSCT}

2OA (a synthetic chemical mimic of lipoic acid-lysine located within the inner domain of PDC-E2) was coupled to bovine serum albumin (2OA-BSA) as previously described [32]. For the induction of autoimmune cholangitis, $100 \mu \mathrm{g}$ 2OA-BSA conjugate (in $50 \mu \mathrm{L}$ phosphate-buffered saline, or PBS) was emulsified with $50 \mu \mathrm{L}$ of complete Freund's adjuvant (containing $1 \mathrm{mg} / \mathrm{mL}$ of mycobacterium tuberculosis strain H37RA, Sigma-Aldrich) and injected intraperitoneally (I.P.) into female C57BL/6 mice. Additionally, mice received $100 \mathrm{ng}$ of pertussis toxin (List Biological Laboratories, Campbell, CA, USA) in $100 \mu \mathrm{L}$ PBS I.P. at the time of initial immunization with 2OA-BSA and 2 days afterwards, respectively. Two weeks later, the mice were re-boosted I.P. with $100 \mu \mathrm{g}$ 2OA-BSA in $50 \mu \mathrm{L}$ PBS emulsified with $50 \mu \mathrm{L}$ of incomplete Freund's adjuvant (Sigma-Aldrich). The treatment of UC-MSCT in 2OA-BSA-immunized mice was performed after the onset of disease (that is, 8 weeks after immunization). Mice were injected intravenously with $1 \times 10^{6} \mathrm{UC}-\mathrm{MSCs}$ and sacrificed 12 weeks after immunization.

\section{Serum biochemical markers, anti-PDC-E2 antibody, and cytokine measurement}

The serum levels of alanine aminotransferase (ALT), aspartate aminotransferase (AST), alkaline phosphatase (ALP), and glutamyl transpeptidase (GGT) were determined by using detection kits (Jiancheng Bioengineering Institute, Nanjing, Jiangsu, China). The serum anti-PDC-E2 autoantibodies (LifeSpan Biosciences, Seattle, WA, USA) and human Gal-9 (RayBiotech, Norcross, GA, USA) in UC-MSC conditioned media (CM) were measured by 
enzyme-linked immunosorbent assay (ELISA) kits. Serum levels of IFN- $\gamma$, interleukin-17A (IL-17A), IL-12, and IL-23 were measured by using Milliplex Cytokine kits with Luminex (Millipore, Billerica, MA, USA). All procedures were performed in accordance with the instructions of the manufacturer.

\section{Histological analysis}

Murine livers were harvested immediately after sacrifice, and aliquots were fixed in $10 \%$ buffered formalin at room temperature for 2 days, embedded in paraffin, and cut into $4 \mu \mathrm{m}$ sections for routine hematoxylin (Dako Cytomation, Carpinteria, CA, USA) and eosin (American Master Tech Scientific, Lodi, CA, USA) (H\&E) staining. Standard pathologic evaluation by light microscopy was performed for H\&E-stained sections, and the relative levels of liver inflammation and biliary cell damage were recorded. Each section was scored as $0=$ no pathologic change, $1=$ minimal, 2 = mild, 3 = moderate, or $4=$ severe in accordance with a widely accepted scoring system [33].

\section{Cell preparation and flow cytometry analysis}

Livers, spleens, and peripheral blood were harvested immediately following sacrifice of the mice. Livers were first perfused with PBS containing 0.2\% BSA (0.2\% BSA/ PBS), passed through a $100 \mu \mathrm{m}$ nylon cell strainer, and re-suspended in $0.2 \%$ BSA/PBS. Hepatocytes were removed as pellets after centrifugation at $75 \mathrm{~g}$ for $1 \mathrm{~min}$, and the remaining suspended cells were collected. Spleens were disrupted between two glass slides and suspended in $0.2 \%$ BSA/PBS. Mononuclear cells from the livers were isolated by gradient centrifugation using $40 \%$ and $70 \%$ Percoll (Sigma-Aldrich). Peripheral blood mononuclear cells were obtained by lysis of erythrocytes in the blood. The following antibodies were used: anti-CD4, anti-IL17A, and anti-IFN- $\gamma$ (eBioscience, San Diego, CA, USA). For intracellular cytokine staining, cells were stimulated with $20 \mathrm{ng} / \mathrm{mL}$ phorbol-12-myristate-13-acetate plus $1 \mu \mathrm{g} / \mathrm{mL}$ ionomycin at $37{ }^{\circ} \mathrm{C}$ for $4-5 \mathrm{~h}$ in the presence of $5 \mu \mathrm{g} / \mathrm{mL}$ brefeldin A (all from Enzo Life Science, Farmingdale, NY, USA). Then the cells were fixed and permeabilized with a fixation/permeabilization kit (NordicMUbio, Maastricht, Limburg, the Netherlands), followed by staining with anti-IFN- $\gamma$ or anti-IL-17A. Data were acquired by a FACS Calibur flow cytometer (BD Biosciences, Mountain View, CA, USA) and were analyzed with FlowJo software (Tree Star, Ashland, OR, USA).

\section{Cell labeling with GFP}

To track the transplanted cells in vivo, UC-MSCs were labeled with green fluorescent protein (GFP) by lentivirus infection. Briefly, the pLV-CMV-GFP-Neo vector, PMD2.G and PSPAX2 packaging plasmids, and the
X-treme GENE HP DNA Transfection Reagent (Roche, Basel, Switzerland) were added to 10\% FBS Dulbecco's Modified Eagle Medium, mixed gently, and incubated at room temperature for $20 \mathrm{~min}$. The mixture was added dropwise into $293 \mathrm{~T}$ cells in a $10-\mathrm{cm}$ plate. After $48 \mathrm{~h}$ of incubation, the virus supernatant was collected and filtered by using a $0.45-\mathrm{mm}$ filter. UC-MSCs were then infected with the virus. After being co-cultured for $48 \mathrm{~h}$, the aminoglycoside antibiotic G418 (Gibco-BRL, Carlsbad, CA, USA) was added to the medium at a final concentration of $600 \mathrm{mg} / \mathrm{mL}$ to select UC-MSCs with a stable GFP expression. The UC-MSCs labeled with GFP were observed with a fluorescence emission ratio at $530 \mathrm{~nm}$ by using an epifluorescence microscope and an excitation wavelength of $488 \mathrm{~nm}$.

\section{Immunofluorescence}

For the immunofluorescence examination, liver tissues were OCT-embedded, snap-frozen, and cut into $3 \mu \mathrm{m}$ slides. Then slides were incubated with primary antibody overnight at $4{ }^{\circ} \mathrm{C}$. Primary antibodies were as follows: Gal-9 (1:200; abcam, Cambridge, MA, USA). Slides were stained with 4',6-diamidino-2-phenylindole (DAPI) and then examined by fluorescence microscope. The scale bar of the picture at $200 \times$ magnification represents $50 \mu \mathrm{m}$.

\section{Isolation and culture of naïve $\mathrm{CD}^{+}{ }^{+} \mathrm{T}$ cells}

Differentiation of murine Th1 and Th17 cells was performed as previously described [34, 35]. Briefly, for Th1 cell differentiation, naïve $\mathrm{CD}^{+} \mathrm{T}$ cells were purified from spleens by using a naïve $\mathrm{CD}^{+}{ }^{+} \mathrm{T}$ cell Isolation Kit (Stem Cell Technologies, Vancouver, BC, Canada) and were cultured in $2.5 \mu \mathrm{g} / \mathrm{mL}$ anti-CD3 and $5 \mu \mathrm{g} / \mathrm{mL}$ anti-CD28 (eBioscience) pre-coated culture plates with 20 ng/mL IL-2 (PeproTech), 20 ng/mL IL-12 (PeproTech), and $5 \mu \mathrm{g} / \mathrm{mL}$ anti-IL-4 (eBioscience) for stimulation. For Th17 cell differentiation, naïve $\mathrm{CD}^{+} \mathrm{T}$ cells received the same treatment as for Th1 differentiation except 20 ng/mL IL-6 (PeproTech), 3 ng/mL transforming growth factor-beta (TGF- $\beta$ ) (PeproTech), $20 \mathrm{ng} / \mathrm{mL}$ IL-23 (PeproTech), $5 \mu \mathrm{g} / \mathrm{mL}$ anti-IFN- $\gamma$ (eBioscience), and $5 \mu \mathrm{g} / \mathrm{mL}$ anti-IL-4 (eBioscience) were used for stimulation instead. To confirm the role of Gal-9 in UC-MSCs, the cells were treated with UC-MSCs alone or UC-MSCs plus $10.8 \mathrm{mg} / \mathrm{mL} \alpha$-lactose (Sigma-Aldrich). After culture for $72 \mathrm{~h}$, the cells were collected for further analysis.

\section{Proliferation assay}

Murine $\mathrm{CD}^{+} \mathrm{T}$ cells were purified from spleens in accordance with the instructions of the manufacturer (BD Biosciences). For the proliferation assay, $\mathrm{CD} 4^{+} \mathrm{T}$ cells at a density of $1 \times 10^{6}$ cells per well were labeled with 
$5 \mu \mathrm{M}$ carboxyfluorescein diacetate succinimidyl ester (CFSE) (Invitrogen, Camarillo, CA, USA) and then cocultured with UC-MSCs $\left(1 \times 10^{5}\right.$ cells per well $)$ or UCMSCs with $10.8 \mathrm{mg} / \mathrm{mL} \alpha$-lactose (Sigma-Aldrich) for 4 days. Cell division was determined by measuring the CFSE fluorescence intensity by flow cytometry.

\section{RNA isolation and real-time polymerase chain reaction}

Total RNA was extracted from liver tissues, UC-MSCs, and BECs by using TRIzol (Vazyme Biotech, Nanjing, Jiangsu, China) and reverse-transcribed by PrimeScript ${ }^{\text {tw }} \mathrm{RT}$ Master Mix (Vazyme Biotech). Quantitative real-time polymerase chain reaction (PCR) assays using gene-specific primers (Table 1) and SYBR Premix Ex Taq kit (Vazyme Biotech) were run on StepOnePlus ${ }^{\text {Tu }}$ Real Time PCR Systems (Applied Biosystems, Foster City, CA, USA). The relative expression of each gene was determined and normalized to the expression of glyceraldehyde 3-phosphate dehydrogenase (GAPDH). Relative quantification was calculated by using the $2^{-\Delta \Delta \mathrm{Ct}}$ method.

\section{Western blot assay}

For Western blot assay, rabbit anti-Gal-9 antibody (Proteintech, Wuhan, Hubei, China), rabbit antibodies to the kinases c-Jun N-terminal kinase (JNK), phospho-JNK, p38/mitogen-activated protein kinase (p38/MAPK), phospho-p38/
MAPK, extracellular-regulated protein kinase (ERK), phospho-ERK, signal transducer and activator of transcription 1 (STAT1), phospho-STAT1, STAT3, phospho-STAT3, STAT5, phospho-STAT5 (Cell Signaling Technology (CST), Danvers, MA, USA), and mouse anti-GAPDH antibody (Proteintech) were used as primary antibodies. Horseradish peroxidase (HRP)-conjugated anti-rabbit IgG $(\mathrm{H}+\mathrm{L})$ and anti-mouse IgG $(\mathrm{H}+\mathrm{L})$ (Proteintech) were used as secondary antibodies, respectively. UC-MSCs were washed twice with PBS and lysed on ice for $30 \mathrm{~min}$ with $1 \times$ radioimmunoprecipitation assay (RIPA) buffer (CST) containing $1 \%$ 100x protease/phosphatase inhibitor cocktail (CST). Lysates were centrifuged at $12,000 \mathrm{~g}$ at $4{ }^{\circ} \mathrm{C}$ for $20 \mathrm{~min}$, and the supernatants were subjected to sodium dodecyl sulfate-polyacrylamide gel electrophoresis (SDS-PAGE). Protein was transferred to polyvinylidene fluoride membranes (Millipore), blocked for $1 \mathrm{~h}$ in $5 \%$ nonfat milk in TBST (10 mM Tris (BioSharp, Hefei, Anhui, China) (pH 7) and $150 \mathrm{mM} \mathrm{NaCl}, 0.1 \%$ Tween 20), and immunoblotted with the above-listed primary antibodies and appropriate HRP-conjugated secondary antibodies. Chemiluminescence HRP substrate (Millipore) was used to detect the specific proteins, and the bands were visualized by using the G:BOX gel imaging system (Syngene, Cambridge, UK). Analysis was performed by using ImageJ software (National Institutes of Health, Bethesda, MD, USA).

Table 1 Primers for real-time PCR

\begin{tabular}{|c|c|c|}
\hline \multirow[t]{2}{*}{ Genes } & \multicolumn{2}{|l|}{ Primers } \\
\hline & Forward $\left(5^{\prime}-3^{\prime}\right)$ & Reverse $\left(5^{\prime}-3^{\prime}\right)$ \\
\hline Human GAPDH & GCACCGTCAAGGCTGAGAAC & TGGTGAAGACGCCAGTGGA \\
\hline Human Galectin-1 & AGGTTGTTGCTGTCTTTGCC & CAAACCTGGAGAGTGCCTTC \\
\hline Human Galectin-3 & TGCAACCTTGAAGTGGTCAG & GGGGAAGGGAAGAAAGACAG \\
\hline Human Galectin-9 & ATAGTCCCAGAAAAGGGGACA & TCCTAGTGGGTGTGAAAGGC \\
\hline Human CXCL10 & GCTGATGCAGGTACAGCGT & CACCATGAATCAAACTGCGA \\
\hline Human CCL5 & TGTACTCCCGAACCCATTTC & TACACCAGTGGCAAGTGCTC \\
\hline Human CCL20 & CGTGTGAAGCCCACAATAAA & GTGCTGCTACTCCACCTCTG \\
\hline Human CX3CL1 & ACGTGATGTTGCATTTCGTC & CCGATATCTCTGTCGTGGCT \\
\hline Mouse GAPDH & TTGATGGCAACAATCTCCAC & CGTCCCGTAGACAAAATGGT \\
\hline Mouse IFN- $\gamma$ & ATGAACGCTACACACTGCATC & CCATCCTITTGCCAGTTCCTC \\
\hline Mouse IL-17A & TITAACTCCCTTGGCGCAAAA & CTITCCCTCCGCATTGACAC \\
\hline Mouse IL-12 & GCTTCTCCCACAGGAGGTTI & CTAGACAAGGGCATGCTGGT \\
\hline Mouse IL-23 & GCTCCCCTTTGAAGATGTCA & GACCCACAAGGACTCAAGGA \\
\hline Mouse T-bet & ATCCTGTAATGGCTTGTGGG & TCAACCAGCACCAGACAGAG \\
\hline Mouse RORyt & GGTGATAACCCCGTAGTGGA & CTGCAAAGAAGACCCACACC \\
\hline Mouse CXCL10 & CCTATGGCCCTCATTCTCAC & CTCATCCTGCTGGGTCTGAG \\
\hline Mouse CCL5 & CCACTTCTTCTCTGGGTTGG & GTGCCCACGTCAAGGAGTAT \\
\hline Mouse CCL20 & TGTACGAGAGGCAACAGTCG & TCTGCTCTTCCTTGCTTTGG \\
\hline Mouse CX3CL1 & TGGGATTCGTGAGGTCATCT & CGCGTTCTTCCATTTGTGTA \\
\hline
\end{tabular}




\section{Statistical analysis}

Data are presented as the mean \pm standard error of the mean (SEM). Student's $t$ test was applied when two groups were compared for significant differences. A one-way analysis of variance (ANOVA) followed by the Newman-Keuls test was used to compare more than two groups. The Prism statistical package (GraphPad Software Inc., La Jolla, CA, USA) was used. A $P$ value of less than 0.05 was considered statistically significant.

\section{Results}

\section{UC-MSCT alleviates 2OA-BSA-induced autoimmune cholangitis}

To examine the potential therapeutic effect of UC-MSCs in $\mathrm{PBC}$, we used the standard protocol to induce cholangitis in mice by 2OA-BSA immunization (Fig. 1a). As shown in Fig. 1b and c, intravenous UC-MSCT significantly mitigated the severity of liver inflammation and bile duct damage by histological analysis. The amelioration was further confirmed by reduced levels of ALT, AST, ALP, and GGT as compared with untreated mice (Fig. 1d). More importantly, anti-PDC-E2 autoantibodies in the serum were significantly decreased after UC-MSCT (Fig. 1e). These results indicated that UC-MSCT effectively suppressed disease development in the experimental autoimmune cholangitis mice.

\section{UC-MSCT inhibits the aberrant Th1 and Th17 responses in 2OA-BSA-induced autoimmune cholangitis}

As shown in Fig. 2a-d, UC-MSCT significantly decreased the infiltration of Th1 and Th17 cells in the liver, spleen, and peripheral blood in 2OA-BSA-immunized mice. Although the frequencies of Th2 cells did not change, UC-MSCT remarkably downregulated the Th1/Th2 ratio (Additional file 1: Figures S1 and S2). Besides, we confirmed that the infusion of UC-MSCs into normal C57BL/6 mice did not induce cross-species immunoreaction (Additional file 1: Figure S3). We then analyzed the mRNA expressions of IFN- $\gamma$, IL-12, IL-17A, and IL-23 in liver and found that these cytokines were downregulated in the UC-MSCT group. In addition, UC-MSCT suppressed the mRNA expression of T-bet and RAR-related orphan receptor gamma $t(R O R \gamma t)$, the most important transcription factors for Th1 and Th17 cells, respectively (Fig. 2e). Consistently, quantification of IFN- $\gamma$, IL-12, IL-17A, and IL-23 expression revealed that UC-MSCT significantly decreased their levels in the serum (Fig. 2f). Therefore, the above data indicated that a

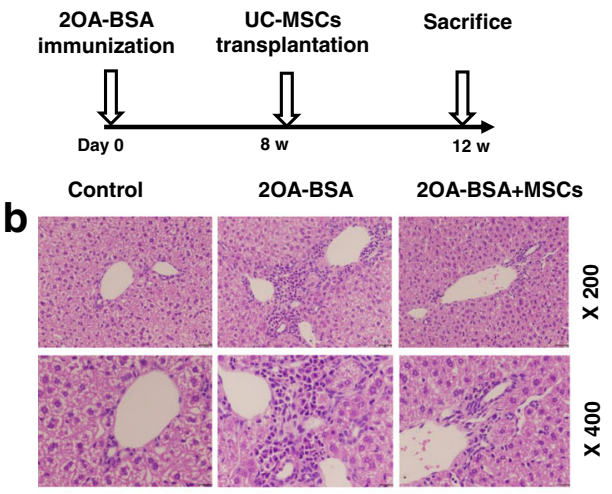

C

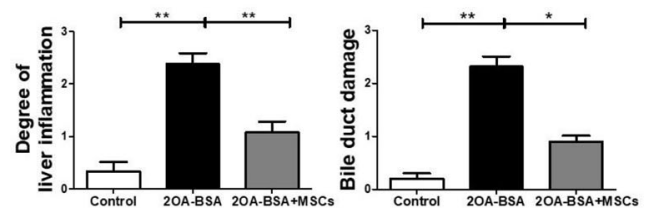

d

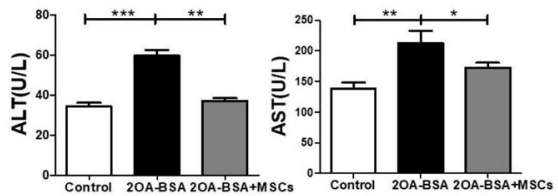

ষ্ণ

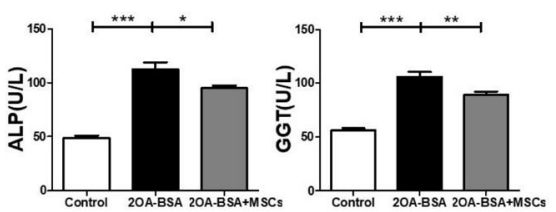

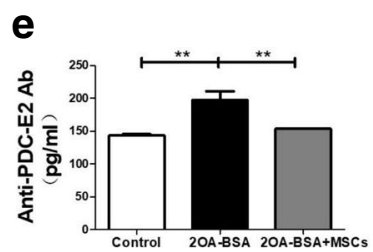

Fig. 1 Umbilical cord-derived mesenchymal stem cell transplantation alleviates 2-octynoic acid coupled to bovine serum albumin (2OA-BSA)-induced autoimmune cholangitis. a Schematic illustration of the experimental procedure. $\mathbf{b}$ Representative images of liver tissue sections by hematoxylin-and-eosin staining from control, primary biliary cholangitis, or umbilical cord-derived mesenchymal stem cell (UC-MSC)-treated mice, showing liver inflammation and the extent of bile duct damage. $\mathbf{c}$ Histological scores were assessed on the basis of lymphocytic infiltration and bile duct damage in the liver. $\mathbf{d}$ The serum levels of alanine aminotransferase (ALT), aspartate aminotransferase (AST), alkaline phosphatase (ALP), and glutamyl transpeptidase (GGT) were measured. e The levels of anti-PDC-E2 autoantibodies were measured. Bars represent the mean \pm standard error of the mean (SEM); $n=6$ per group. ${ }^{*} P<0.05,{ }^{*} P<0.01,{ }^{* *} P<0.001$ 


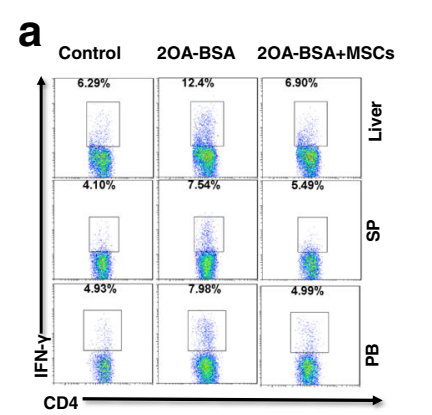

C Control 2OA-BSA 2OA-BSA+MSCs

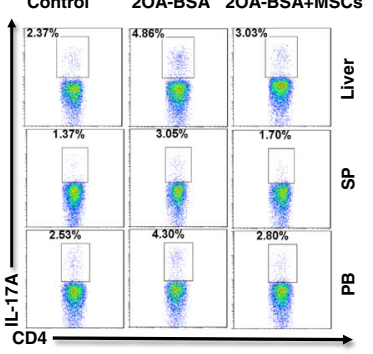

b

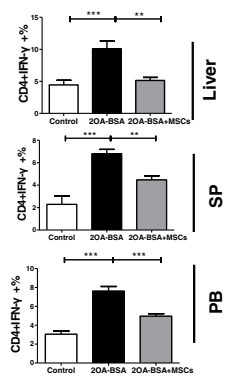

d

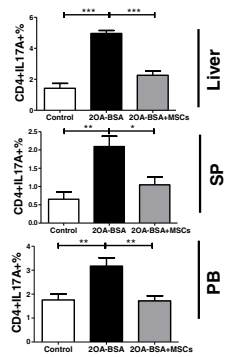

e
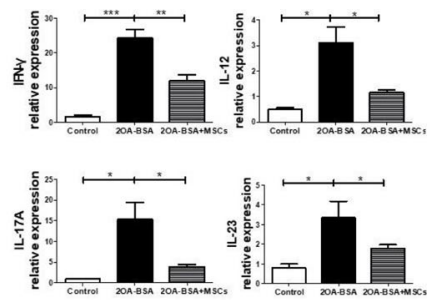

(1)
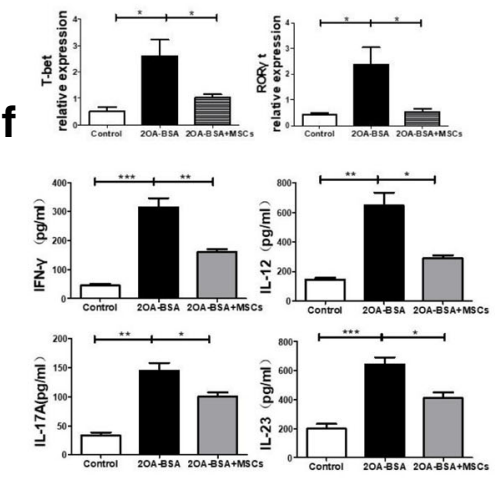

Fig. 2 Umbilical cord-derived mesenchymal stem cell transplantation inhibits the aberrant Thelper 1 (Th1) and Th17 responses in 2-octynoic acid coupled to bovine serum albumin (2OA-BSA)-induced autoimmune cholangitis. a Representative flow cytometric profiles showing the frequencies of Th1 cells in the liver, spleen, and blood. $\mathbf{b}$ The frequencies of Th1 cells were quantified. c Representative flow cytometric profiles showing the frequencies of Th17 cells in the liver, spleen, and blood. $\mathbf{d}$ The frequencies of Th17 cells were quantified. e Intrahepatic mRNA expressions of interferon-gamma (IFN- $\gamma$ ), interleukin-17A (IL-17A), IL-12, IL-23, T-bet, and RAR-related orphan receptor gamma t (RORyt) were determined by real-time polymerase chain reaction. $\mathbf{f}$ Levels of IFN- - , IL-17A, IL-12, and IL-23 in serum were detected by Luminex. Bars represent the mean \pm standard error of the mean (SEM); $n=6$ per group. ${ }^{*} P<0.05,{ }^{* *} P<0.01,{ }^{* *} P<0.001$. Abbreviations: $P B$ peripheral blood, $S P$ spleen

UC-MSCT resulted in attenuation of the Th1 and Th17 immune responses in 2OA-BSA-immunized mice.

\section{Gal-9 is highly expressed in UC-MSCs}

IFN- $\gamma$ was reported to be overexpressed in the serum and liver of patients with PBC [36]. Although inflammatory factors affect the immunomodulatory effects of MSCs [37], it is still unknown whether this immunoregulatory activity could be affected by IFN- $\gamma$ in the context of PBC. Prostaglandin E2 (PGE2) [22], nitric oxide [23], and indoleamine-pyrrole 2,3-dioxygenase (IDO) [24] have been demonstrated to be involved in the functions of MSCs. Nevertheless, blockage of any one of these molecules is insufficient to completely abolish the immunoregulatory effects of MSCs, indicating that some other important mediators may also play a role. Previous studies have found that human bone marrow-derived MSCs (BM-MSCs) could secrete Gal-1 or Gal-3 to exert immunomodulatory functions $[38,39]$. However, whether the Galectin family member acts as a major effector in the process of UC-MSC immunomodulation is still to be elucidated.

We then attempted to investigate the expression of Gal-1, Gal-3, and Gal-9 in the UC-MSCs after IFN- $\gamma$ stimulation. The results showed that only Gal-9 significantly increased after IFN- $\gamma$ stimulation (Fig. 3a), further confirmed by the ELISA and Western blot assay (Fig. 3b, c). Meanwhile, we detected that a portion of UC-MSCs were localized in the liver, which indicated that UC-MSCs could migrate to the liver injury site. Moreover, double-positive yellow cells with a stretching morphology were observed in UC-MSC-infused livers, which suggested that UC-MSCs could express Gal-9 efficiency in vivo (Fig. 3d). Intriguingly, the concentration of Gal-9 was shown to significantly increase in the UC-MSC-treated PBC mouse model, in both the serum and livers (Additional file 1: Figure S4).

\section{Via Gal-9, UC-MSCs suppress CD4 ${ }^{+}$T-cell proliferation as well as Th1 and Th17 cell differentiation}

Next, we aimed to explore whether Gal-9 contributed to the immunomodulatory properties of UC-MSCs. UCMSCs significantly inhibited the proliferation of $\mathrm{CD}^{+} \mathrm{T}$ cells by decreasing about $30 \%$; in contrast, this effect was impaired after adding $\alpha$-lactose, a natural inhibitor of Gal-9 (Fig. 4a). Furthermore, the differentiation of Th1 and Th17 cells was inhibited in the presence of UC-MSCs from $16.5 \%$ to $5.54 \%$ and $8.48 \%$ to $4.11 \%$, respectively. However, upon the addition of $\alpha$-lactose, the proportions of Th1 and Th17 cells reversely increased about 

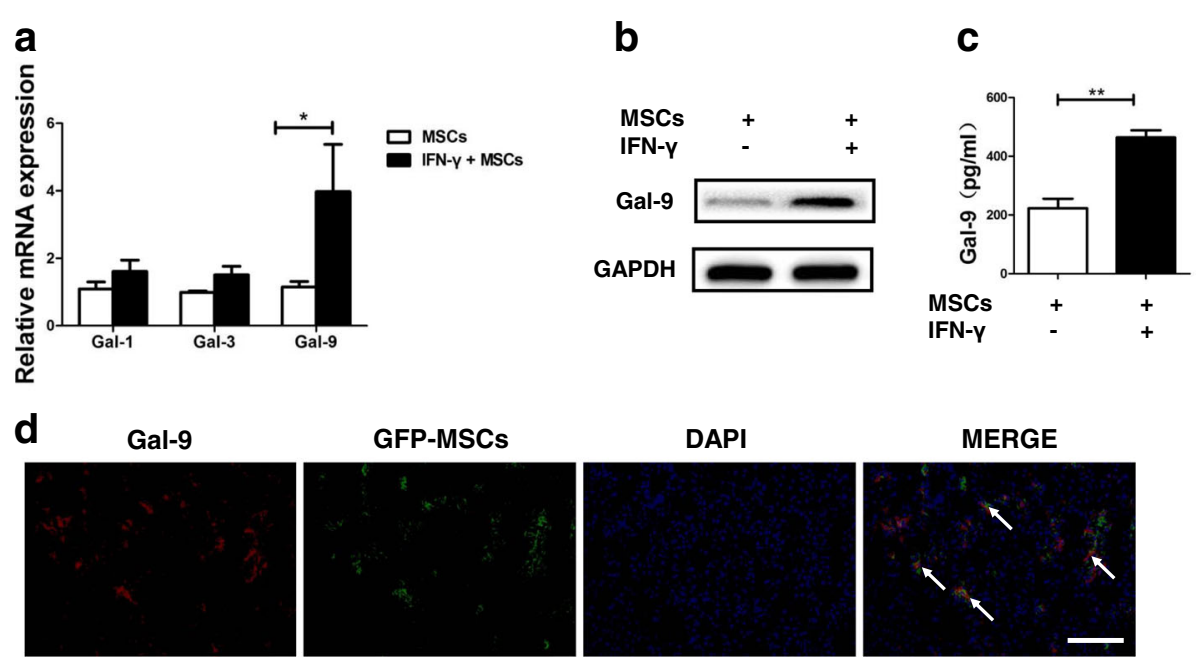

Fig. 3 Galectin-9 (Gal-9) is highly expressed in umbilical cord-derived mesenchymal stem cells (UC-MSCs). a Total mRNA of UC-MSCs was extracted after activation with or without interferon-gamma (IFN- $\gamma$ ) and analyzed by real-time polymerase chain reaction for the expression of Gal-1, Gal-3, and Gal-9. Bars represent the mean \pm standard error of the mean (SEM); $n=4$ per group. $\mathbf{b}, \mathbf{c}$ UC-MSCs were treated with or without IFN- $\gamma$ and analyzed by Western blot and enzyme-linked immunosorbent assay for the expression of Gal-9. Bars represent the mean \pm SEM; $n=3$ per group. $\mathbf{d}$ The fluorescence microscope was employed to detect green fluorescent protein (GFP)-positive UC-MSCs in the livers of primary biliary cholangitis mice. Colocalization (white arrow) of the GFP (green) with Gal-9 (red) staining indicated that UC-MSCs expressed Gal-9. Scale bar $=50 \mu \mathrm{m}$. Abbreviation: DAPI 4',6-diamidino-2-phenylindole

$50 \%$ (Fig. 4b, c). Since UC-MSCs secrete the soluble form of Gal-9, we treated the cells with CM collected from UC-MSCs. We found that MSC-CM also significantly inhibited $\mathrm{CD}^{+}$cell proliferation (Additional file 1: Figure S5a) and downregulated the percentage of Th1 and Th17 cells; moreover, the addition of $\alpha$-lactose blocked the inhibitory effects of MSC-CM (Additional file 1: Figure S5b, c). Taken together, these results provided evidence that Gal-9 participated in the immunoregulatory functions of UC-MSCs by mediating the proliferation and differentiation of T-cell populations.

\section{UC-MSCT downregulates proinflammatory chemokines to repress inflammatory responses}

Chemokines direct migration and localization of lymphocytes within tissues, thus playing important roles in regulating inflammatory responses [40]. To ascertain whether UC-MSCs affect the expression of chemokines, we further measured the hepatic mRNA expression of several proinflammatory chemokines in vivo. As shown in Fig. 5a-d, UC-MSCT significantly downregulated the intrahepatic mRNA expressions of CCL5, CCL20, CXCL10, and CX3CL1. Notably, the expression of CXC3CL1 and CCL20 decreased by about 50\% after UC-MSCT. To further evaluate whether UC-MSCs protected the BECs through Gal-9, we co-cultured UCMSCs with BECs before IFN- $\gamma$ stimulation in vitro to examine the alteration of these chemokines. Expression of CCL5, CCL20, CXCL10, and CX3CL1 mRNA was significantly reduced in BECs after UC-MSC treatment, while this cytoprotective function of UC-MSCs was impaired after the addition of $\alpha$-lactose (Fig. 5e-h). Thus, these data implied that inflammatory cytokines stimulated chemokine expression by BECs, leading to the recruitment of Th1 and Th17 cells to the bile ducts. UC-MSCs could reduce these proinflammatory chemokines to suppress aberrant lymphocytic infiltration with Gal-9 participating in this process.

\section{Upregulation of Gal-9 in UC-MSCs induced by IFN- $-\gamma$ is mediated through JNK and STAT signaling pathways}

To elucidate the possible signaling pathways involved in IFN- $\gamma$-induced Gal-9 expression, various signaling pathways were investigated. The administration of IFN- $\gamma$ effectively activated the STATs (STAT1, STAT3, and STAT5) and JNK signaling pathways in UC-MSCs, whereas the expression of p38/MAPK and ERK was not significantly changed by Western blot (Fig. 6a). In an effort to verify these results, UC-MSCs were treated with SP600125 (JNK inhibitor) or AG490 (STAT inhibitor) upon IFN- $\gamma$ stimulation and were assessed to detect Gal-9 expression. As shown in Fig. 6b, we found that SP600125 and AG490 significantly suppressed the production of Gal-9 in UC-MSCs, indicating that the induction of Gal-9 was likely to be regulated by the STAT and JNK signaling pathways.

\section{Discussion}

In the present study, we demonstrated that UC-MSCT was able to attenuate the development of 2OA-BSA- 

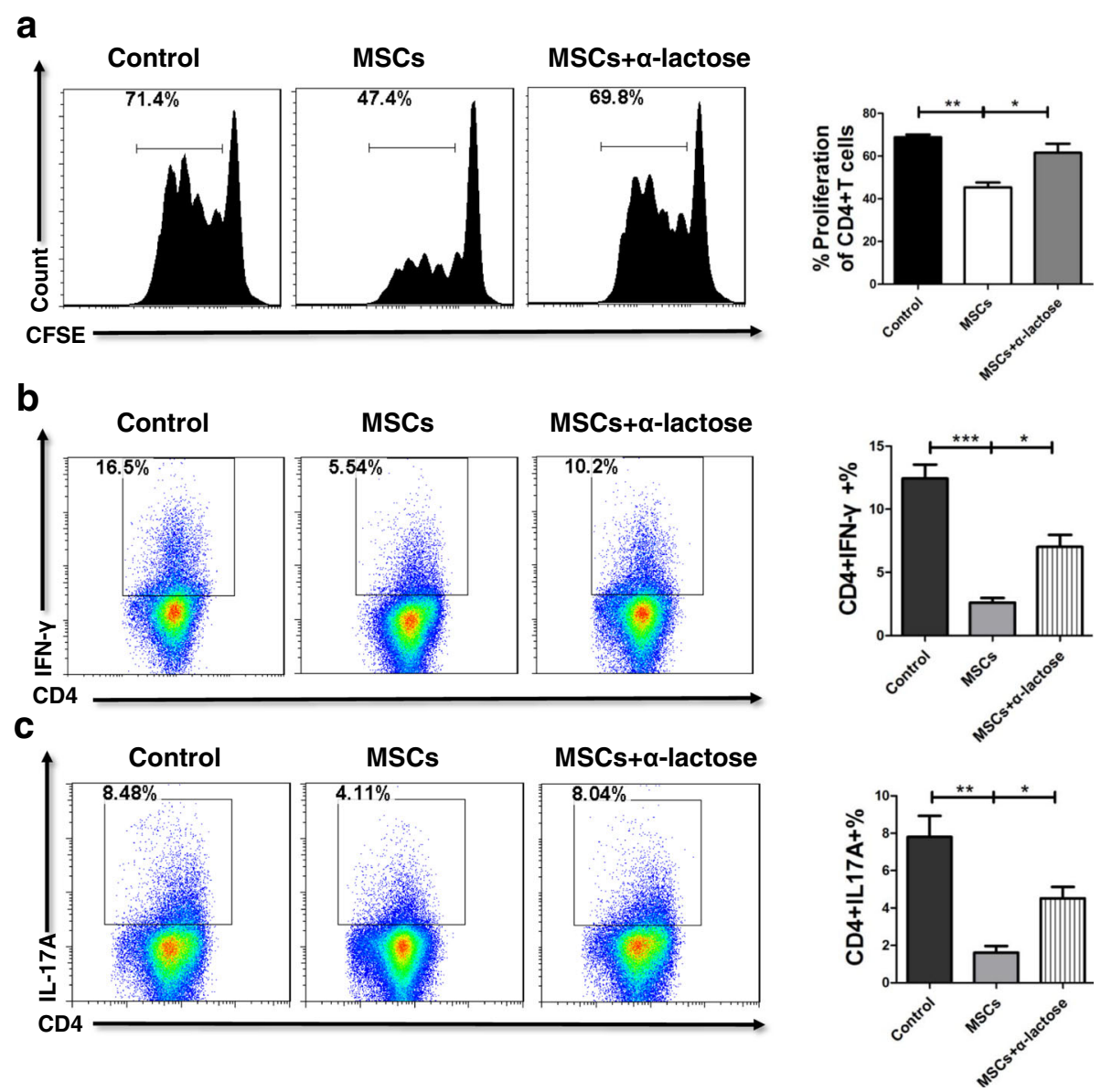

Fig. 4 Umbilical cord-derived mesenchymal stem cells (UC-MSCS) suppress CD4 ${ }^{+}$T-cell proliferation as well as Thelper 1 (Th1) and Th17 cell differentiation via galectin-9. a Carboxyfluorescein diacetate succinimidyl ester (CFSE)-labeled CD4 ${ }^{+} \mathrm{T}$ cells were cultured in the presence of UC-MSCs or UC-MSCs plus a-lactose for 4 days. The proliferation of murine CD4 ${ }^{+} T$ cells was assessed on the basis of the fluorescence intensity of CFSE. Bars represent the mean \pm standard error of the mean (SEM); $n=3$ per group. b Purified naïve murine $C D 4^{+} T$ cells were cultured under Th1 polarization conditions in the presence of UC-MSCs or UC-MSCs plus a-lactose. Representative flow cytometric profiles that show the frequencies of Th1 cells are presented. The frequencies of Th1 cells were quantified. c Purified naïve murine CD4 ${ }^{+} \mathrm{T}$ cells were cultured under Th17 polarization conditions in the presence of UC-MSCs or UC-MSCs plus a-lactose. Representative flow cytometric profiles that show the frequencies of Th17 cells are presented. The frequencies of Th17 cells were quantified. Bars represent the mean $\pm \mathrm{SEM} ; n=4$ per group. ${ }^{*} P<0.05,{ }^{* *} P<0.01,{ }^{* * *} P<0.001$

induced autoimmune cholangitis by inhibiting immune response mediated by Th1/Th17 cells and downregulating chemokine activities. Furthermore, our data also indicated that the regulation of $\mathrm{CD} 4^{+} \mathrm{T}$-cell proliferation, the differentiation of Th1 and Th17 cells, and the cytoprotection by UC-MSCs were dependent on Gal-9, the production of which involved the STAT and JNK signaling pathways.

PBC is an autoimmune disease associated with organ-specific and systemic autoimmunity. Autoreactive $\mathrm{CD}^{+} \mathrm{T}$ cells have been linked to the pathogenesis of PBC. Th1 cells with their signature cytokine IFN- $\gamma$ as well as Th17 cells with IL-17A are thought to be the main pathogenic mediators in PBC [41]. Here, we used a well-recognized murine model of autoimmune cholangitis to investigate the potential therapeutic effects of UC-MSCT and its underlying mechanism. In this study, on one hand, UC-MSCT decreased the frequencies of Th1 and Th17 cells in both systemic and local tissues in 2OA-BSA-immunized mice; on the other hand, UC-MSCT suppressed the expression of inflammatory chemokines. Previous studies have reported that upregulation of regulatory $\mathrm{T}$ (Treg) cells is one important aspect of MSC-mediated immunomodulation [42]. Accordingly, we also examined the alteration of Treg cells and found that the frequency of Treg cells in the peripheral blood was elevated after UC-MSCT, which suggested that the diminished Th1 and Th17 cell responses in the peripheral blood were due in part to the expansion of Treg cells (Additional file 1: Figure S6). 


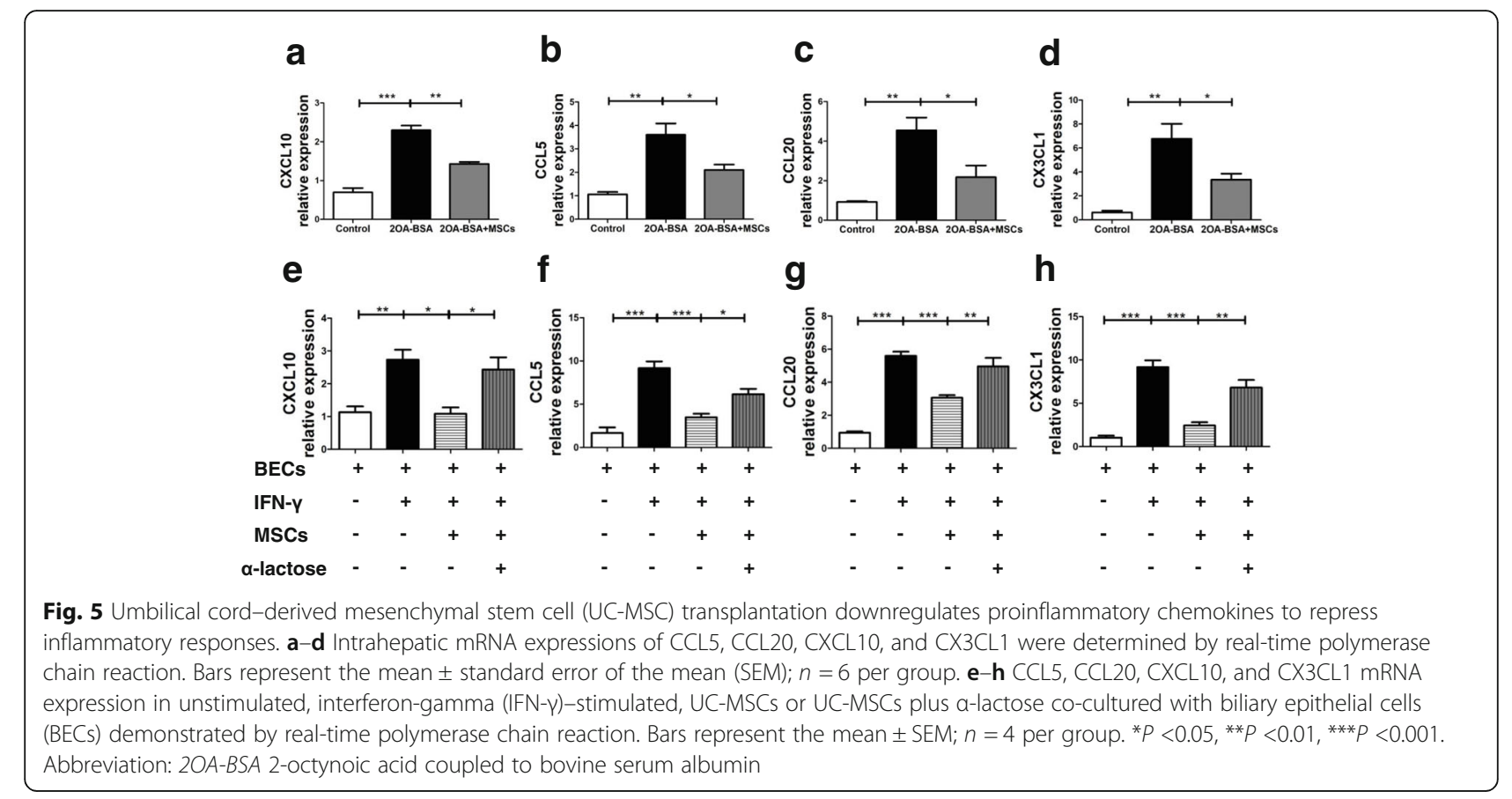

It is well known that MSCs require proinflammatory cytokines to induce their immunosuppressive function [43]. Galectins, a family of beta-galactoside-binding proteins, have emerged as one of the main regulators of the MSC immunosuppressive function [44]. Gal-9 is a unique member of this family and has a wide variety of biological functions in innate and adaptive immunity $[45,46]$. Gal-9 was strongly induced in human BM-MSCs [47]. Ungerer et al. demonstrated that Gal-9 was a major mediator of the anti-proliferative effects of BM-MSCs [48]. Here, we

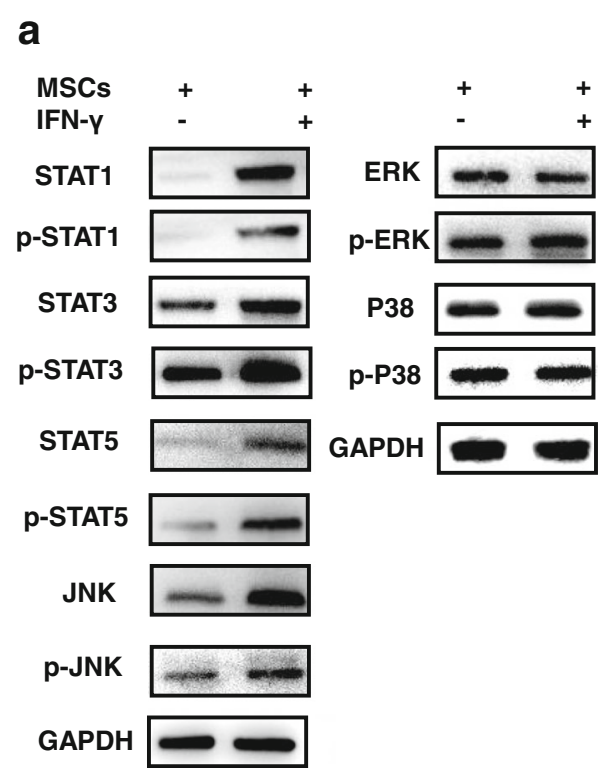

b

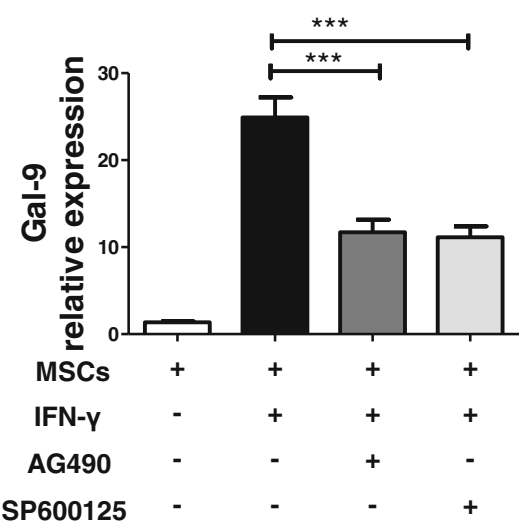

Fig. 6 Interferon-gamma (IFN- - )-induced galectin-9 (Gal-9) upregulation of umbilical cord-derived mesenchymal stem cells (UC-MSCs) is mediated through the c-Jun N-terminal kinase (JNK) and signal transducer and activator of transcription (STAT) signaling pathways. a The expression of STAT, p38/mitogen-activated protein kinase (p38/MAPK), extracellular-regulated protein kinase (ERK), JNK, and their phosphorylation forms were detected by Western blot analysis in unstimulated and IFN- $\gamma$-stimulated UC-MSCS. $\mathbf{b}$ Total mRNA of UC-MSCs was extracted after the activation of IFN- $\gamma$ with JNK or STAT inhibitors and then analyzed by real-time polymerase chain reaction for the expression of Gal-9. Bars represent the mean \pm standard error of the mean (SEM); $n=3$ per group. ${ }^{* * *} P<0.001$ 
found that Gal-9 was constitutively expressed in UCMSCs and that IFN- $\gamma$ stimulation could induce substantially higher Gal-9 expression in UC-MSCs. Of interest, we found that the amount of IFN- $\gamma$-positive cells was widely distributed around interlobular bile ducts of the PBC mouse model (Additional file 1: Figure S7) and the expression of Gal-9 was elevated after UC-MSCT, further supporting the concept that the disease-specific microenvironment is crucial for the therapeutic effects of implanted MSCs.

According to current knowledge, MSCs may exert their therapeutic effects in two ways: by cell replacement or in a paracrine manner. The relative importance of these two mechanisms is still a topic of controversy [49-51]. In the present study, it was noticed that the number of transplanted UC-MSCs decreased gradually with time but that the expression of Gal-9 was significantly increased (Additional file 1: Figure S8). Considering the histological and serological improvement by UC-MSCT lasted for a long term while only a small portion of UC-MSCs were observed in the liver within 7 days after infusion, we speculated that the beneficial effects of UC-MSCs on the recovery of liver injury may be attributed to their secretome of soluble factors, such as Gal-9. Mechanistically, the results of our in vitro studies indicated that UC-MSC-derived Gal-9 could suppress the proliferation and differentiation of $\mathrm{CD} 4^{+} \mathrm{T}$ cells and thereby alleviate experimental autoimmune cholangitis.

Chemokines represent one kind of major mediators of innate immunity as they play a key role in the selective recruitment of immune cells during localized inflammatory responses [52]. The potential contribution of chemokines and inflammation to the progression of $\mathrm{PBC}$ in the chemokine-chemokine receptor network may provide important clues in the injury of BECs in PBC [53-55]. Our data showed that UC-MSCT decreased the expression of these proinflammatory chemokines; however, this cytoprotective function was impaired after the inhibition of Gal-9, which suggests that UC-MSCs could protect damaged BECs in a paracrine manner. Based on these findings, we suppose that $\mathrm{BEC}$-induced chemokines are likely to be active players in $\mathrm{PBC}$ pathogenesis and may elicit the migration and infiltration of autoreactive T cells, which further lead to the liver lesions observed in $\mathrm{PBC}$. Moreover, our results emphasize the potential of the downregulation of specific chemokines as one of the effective ways to modulate inflammatory responses during UC-MSCT.

STAT, p38/MAPK, ERK, and JNK can be activated by IFN- $\gamma$ [56]. These pathways regulate the expression of genes involved in the initiation, propagation, and resolution of immune and inflammatory responses. Thus, the focus of this study was to explore whether the IFN- $\gamma-$ induced expression of Gal-9 in UC-MSCs depends upon these kinase pathways. We demonstrated that treatment with STAT and JNK inhibitors effectively repressed Gal-9 expression induced by IFN- $\gamma$ in UC-MSCs. To the best of our knowledge, this is the first study to demonstrate that the induction of Gal-9 in UC-MSCs is mediated by the activation of the STAT and JNK signaling pathways.

\section{Conclusions}

In summary, the present study shows that UC-MSCs exert profound inhibitory effects on inflammatory responses to alleviate liver injury in experimental autoimmune cholangitis mice. Furthermore, UC-MSCs inhibit Th1 and Th17 cell responses as well as aberrant chemokine activities through Gal-9-mediated immunosuppression. Additionally, the induction of Gal-9 in UC-MSCs is mediated by the STAT and JNK signaling pathways. Our results provide novel insights into the clinical application of UC-MSCs in the treatment of PBC.

\section{Additional files}

Additional file 1: Figure S1. Umbilical cord-derived mesenchymal stem cell transplantation does not influence Th2 cells. $n=6$; Bars represent the mean \pm SEM; Abbreviations: PB peripheral blood, SP spleen. Figure S2. Umbilical cord-derived mesenchymal stem cell transplantation downregulates Th1/Th2 ratio. $n=6$; Bars represent the mean $\pm S E M$; ${ }^{*} P<0.05$, ${ }^{*} P<0.01$. Abbreviations: $P B$ peripheral blood, SP spleen. Figure S3. Umbilical cord-derived mesenchymal stem cell transplantation does not affect the Th1 and Th17 immune responses in normal mice. (a, b) The alterations of Th1 and Th17 cells in different groups. $n=4$; Bars represent the mean \pm SEM; Abbreviations: PB peripheral blood, SP spleen. Figure S4. Umbilical cord-derived mesenchymal stem cell transplantation upregulates the expression of galectin-9 (Gal-9). a The serum levels of Gal-9 in different groups. $n=6$. $\mathbf{b}$ The liver expression of Gal-9 in different groups. $n=3$; Bars represent the mean \pm SEM; ${ }^{* *} P<0.01,{ }^{* *} P<0.001$. Abbreviation: GAPDH glyceraldehyde 3-phosphate dehydrogenase. Figure S5. Galectin-9(Gal-9) contributes to the immunoregulatory function of umbilical cord-derived mesenchymal stem cell conditioned media (MSC-CM). (a-c) The proliferation of CD4+ T cells, the alterations of Th1 and Th17 cells in different groups. $n=4$; Bars represent the mean \pm SEM; ${ }^{*} P<0.05,{ }^{* *} P<0.01,{ }^{* *} P<0.001$. Abbreviations: CFSE Carboxyfluorescein diacetate succinimidyl ester. Figure S6. Umbilical cord-derived mesenchyma stem cell transplantation upregulates the regulatory $T$ (Treg) cells. The alterations of Treg cells in different groups. $n=6$; Bars represent the mean \pm SEM; ${ }^{*} P<0.05,{ }^{* *} P<0.01,{ }^{* * *} P<0.001$. Abbreviations: $P B$ peripheral blood, SP spleen. Figure S7. Specific staining of interferon-gamma (IFN- $\gamma$ ) in the liver section. Scale bar $=32 \mu \mathrm{m}$. Figure S8. Dynamic changes of engraftment umbilical cord-derived mesenchymal stem cell (UC-MSC) and galectin-9 (Gal-9) in the liver section. Scale bar $=50 \mu \mathrm{m}$. Abbreviation: GFP+ green fluorescent protein-positive, Gal-9+, galectin-9, DAPI 4',6-diamidino-2-phenylindole. (DOCX $779 \mathrm{~kb}$ )

Additional file 2: Supplementary Materials and Methods. (DOCX 21 kb)

\section{Abbreviations}

2OA-BSA: 2-octynoic acid coupled to bovine serum albumin; ALP: Alkaline phosphatase; ALT: Alanine aminotransferase; AST: Aspartate aminotransferase; BEC: Biliary epithelial cell; BM-MSC: Bone marrow-derived mesenchymal stem cell; CFSE: Carboxyfluorescein diacetate succinimidyl ester; CM: Conditioned media; CST: Cell Signaling Technology; ELISA: Enzyme-linked immunosorbent assay; ERK: Extracellular-regulated protein kinase; FBS: Fetal bovine serum; Gal-9: Galectin-9; GAPDH: Glyceraldehyde 3-phosphate dehydrogenase; GFP: Green fluorescent protein; GGT: Glutamyl transpeptidase; 
H\&E: Hematoxylin and eosin; HRP: Horseradish peroxidase; IFN-ү: Interferongamma; IL: Interleukin; I.P.: Intraperitoneally; JNK: c-Jun N-terminal kinase; MSC: Mesenchymal stem cell; MSCT: Mesenchymal stem cell transplantation; p38/MAPK: p38/mitogen-activated protein kinase; PBC: Primary biliary cholangitis; PBS: Phosphate-buffered saline; PCR: Polymerase chain reaction; STAT: Signal transducer and activator of transcription; Treg: Regulatory $T_{i}$ UC: Umbilical cord; UC-MSC: Umbilical cord-derived mesenchymal stem cell; UC-MSCT: Umbilical cord-derived mesenchymal stem cell transplantation

\section{Acknowledgments}

We thank Hua Song for his contribution of preparing transgenic GFP ${ }^{+}$MSCs and the staff who provided us with the samples of human UCs.

\section{Funding}

This study was supported by the China National Natural Science Foundation (91442119).

\section{Availability of data and materials}

The datasets used or analyzed (or both) during the current study are available from the corresponding author on reasonable request. Supporting data can be obtained from the Additional file 2.

\section{Authors' contributions}

JF designed the study, performed the experiments, analyzed the data, and wrote the manuscript; $X T$ contributed to the study planning and collected and analyzed the data. QW, ZZ, SW, WL, SL, and GY collected and analyzed the data and edited the manuscript. HC and LS edited the manuscript, supervised the study, and provided financial support. All authors read and approved the final manuscript.

\section{Ethics approval and consent to participate}

The animal-related experiments and the isolation of human umbilical cord mesenchymal stem cells were approved by the ethics committee of the Affiliated Drum Tower Hospital of Nanjing University Medical School. All applicable institutional and national guidelines for the care and use of animals were followed.

\section{Consent for publication}

All authors declare their support for the publication and its contents.

\section{Competing interests}

The authors declare that they have no competing interests.

\section{Publisher's Note}

Springer Nature remains neutral with regard to jurisdictional claims in published maps and institutional affiliations.

Received: 5 March 2018 Revised: 9 August 2018 Accepted: 13 August 2018 Published online: 17 September 2018

\section{References}

1. Griffiths L, Dyson JK, Jones DE. The new epidemiology of primary biliary cirrhosis. Semin Liver Dis. 2014;34:318-28.

2. Mousa HS, Carbone M, Malinverno F, Ronca V, Gershwin ME, Invernizzi P. Novel therapeutics for primary biliary cholangitis: toward a disease-stagebased approach. Autoimmun Rev. 2016;15:870-6.

3. Hirschfield GM, Gershwin ME. The immunobiology and pathophysiology of primary biliary cirrhosis. Annu Rev Pathol. 2013;8:303-30.

4. Hirschfield GM, Mason A, Luketic V, Lindor K, Gordon SC, Mayo M, et al. Efficacy of obeticholic acid in patients with primary biliary cirrhosis and inadequate response to ursodeoxycholic acid. Gastroenterology. 2015;148: 751-61 e8.

5. Markham A, Keam SJ. Obeticholic acid: first global approval. Drugs. 2016;76: 1221-6

6. Nevens F, Andreone P, Mazzella G, Strasser SI, Bowlus C, Invernizzi P, et al. A Placebo-Controlled Trial of Obeticholic Acid in Primary Biliary Cholangitis. N Engl J Med. 2016;375:631-43

7. Spacek LA, Solga SF. Obeticholic acid in primary biliary cholangitis. N Engl J Med. 2016;375:e41

8. Chascsa D, Carey EJ, Lindor KD. Old and new treatments for primary biliary cholangitis. Liver Int. 2017;37:490-9.
9. Tyndall A. Mesenchymal stem cell treatments in rheumatology: a glass half full? Nat Rev Rheumatol. 2014;10:117-24.

10. Shi Y, Hu G, Su J, Li W, Chen Q, Shou P, et al. Mesenchymal stem cells: a new strategy for immunosuppression and tissue repair. Cell Res. 2010;20:510-8.

11. Liang J, Zhang H, Hua B, Wang H, Lu L, Shi S, et al. Allogenic mesenchymal stem cells transplantation in refractory systemic lupus erythematosus: a pilot clinical study. Ann Rheum Dis. 2010;69:1423-9.

12. Sun L, Wang $D$, Liang J, Zhang $H$, Feng $X$, Wang $H$, et al. Umbilical cord mesenchymal stem cell transplantation in severe and refractory systemic lupus erythematosus. Arthritis Rheum. 2010;62:2467-75.

13. Xu J, Wang D, Liu D, Fan Z, Zhang H, Liu O, et al. Allogeneic mesenchymal stem cell treatment alleviates experimental and clinical Sjogren syndrome. Blood. 2012:120:3142-51.

14. Liu R, Li X, Zhang Z, Zhou M, Sun Y, Su D, et al. Allogeneic mesenchymal stem cells inhibited $T$ follicular helper cell generation in rheumatoid arthritis Sci Rep. 2015:5:12777.

15. Sun Y, Kong W, Huang S, Shi B, Zhang H, Chen W, et al. Comparable therapeutic potential of umbilical cord mesenchymal stem cells in collageninduced arthritis to TNF inhibitor or anti-CD20 treatment. Clin Exp Rheumatol. 2017;35:288-95.

16. Wang D, Zhang H, Liang J, Gu Z, Ma X, Huang J, et al. Effect of allogeneic bone marrow-derived mesenchymal stem cells transplantation in a polyl:Cinduced primary biliary cirrhosis mouse model. Clin Exp Med. 2011;11:25-32.

17. Wang L, Han Q, Chen H, Wang K, Shan GL, Kong F, et al. Allogeneic bone marrow mesenchymal stem cell transplantation in patients with UDCA-resistant primary biliary cirrhosis. Stem Cells Dev. 2014;23:2482-9.

18. Wang L, Li J, Liu H, Li Y, Fu J, Sun Y, et al. Pilot study of umbilical cordderived mesenchymal stem cell transfusion in patients with primary biliary cirrhosis. J Gastroenterol Hepatol. 2013;28(Suppl 1):85-92.

19. Krampera M, Cosmi L, Angeli R, Pasini A, Liotta F, Andreini A, et al. Role for interferon-gamma in the immunomodulatory activity of human bone marrow mesenchymal stem cells. Stem Cells. 2006;24:386-98.

20. Ryan JM, Barry F, Murphy JM, Mahon BP. Interferon-gamma does not break, but promotes the immunosuppressive capacity of adult human mesenchymal stem cells. Clin Exp Immunol. 2007;149:353-63.

21. Liu Y, Wang L, Kikuiri T, Akiyama $K$, Chen C, Xu X, et al. Mesenchymal stem cell-based tissue regeneration is governed by recipient $\mathrm{T}$ lymphocytes via IFN-gamma and TNF-alpha. Nat Med. 2011:17:1594-601.

22. Nemeth K, Leelahavanichkul A, Yuen PS, Mayer B, Parmelee A, Doi K, et al. Bone marrow stromal cells attenuate sepsis via prostaglandin $\mathrm{E}(2)$-dependent reprogramming of host macrophages to increase their interleukin-10 production. Nat Med. 2009;15:42-9.

23. Sato K, Ozaki K, Oh I, Meguro A, Hatanaka K, Nagai T, et al. Nitric oxide plays a critical role in suppression of T-cell proliferation by mesenchymal stem cells. Blood. 2007:109:228-34.

24. Ling W, Zhang J, Yuan Z, Ren G, Zhang L, Chen X, et al. Mesenchymal stem cells use IDO to regulate immunity in tumor microenvironment. Cancer Res. 2014;74:1576-87.

25. Xu C, Yu P, Han X, Du L, Gan J, Wang Y, et al. TGF-beta promotes immune responses in the presence of mesenchymal stem cells. J Immunol. 2014; 192:103-9.

26. Thijssen VL, Poirier F, Baum LG, Griffioen AW. Galectins in the tumor endothelium: opportunities for combined cancer therapy. Blood. 2007;110:2819-27.

27. Grigorian A, Torossian S, Demetriou M. T-cell growth, cell surface organization, and the galectin-glycoprotein lattice. Immunol Rev. 2009;230:232-46.

28. Sakai K, Kawata E, Ashihara E, Nakagawa Y, Yamauchi A, Yao H, et al. Galectin-9 ameliorates acute GVH disease through the induction of T-cell apoptosis. Eur J Immunol. 2011;41:67-75.

29. Hirao H, Uchida Y, Kadono K, Tanaka H, Niki T, Yamauchi A, et al. The protective function of galectin-9 in liver ischemia and reperfusion injury in mice. Liver Transpl. 2015:21:969-81.

30. Seki M, Oomizu S, Sakata KM, Sakata A, Arikawa T, Watanabe K, et al. Galectin-9 suppresses the generation of Th17, promotes the induction of regulatory $T$ cells, and regulates experimental autoimmune arthritis. Clin Immunol. 2008;127:78-88.

31. Zhao C, Zhang L, Kong W, Liang J, Xu X, Wu H, et al. Umbilical cordderived mesenchymal stem cells inhibit Cadherin-11 expression by fibroblast-like Synoviocytes in rheumatoid arthritis. J Immunol Res. 2015; 2015:137695.

32. Wakabayashi $K$, Lian ZX, Leung PS, Moritoki Y, Tsuneyama K, Kurth MJ, et al. Loss of tolerance in C57BL/6 mice to the autoantigen E2 subunit of 
pyruvate dehydrogenase by a xenobiotic with ensuing biliary ductular disease. Hepatology. 2008;48:531-40.

33. Wu SJ, Yang YH, Tsuneyama K, Leung PS, Illarionov P, Gershwin ME, et al. Innate immunity and primary biliary cirrhosis: activated invariant natural killer T cells exacerbate murine autoimmune cholangitis and fibrosis. Hepatology. 2011;53:915-25.

34. Luz-Crawford P, Noel D, Fernandez X, Khoury M, Figueroa F, Carrion F, et al. Mesenchymal stem cells repress Th17 molecular program through the PD-1 pathway. PLoS One. 2012;7:e45272.

35. Yang M, Deng J, Liu Y, Ko KH, Wang X, Jiao Z, et al. IL-10-producing regulatory B10 cells ameliorate collagen-induced arthritis via suppressing Th17 cell generation. Am J Pathol. 2012;180:2375-85.

36. Kawata K, Tsuda M, Yang GX, Zhang W, Tanaka H, Tsuneyama K, et al. Identification of potential cytokine pathways for therapeutic intervention in murine primary biliary cirrhosis. PLoS One. 2013;8:e74225.

37. Wang Y, Chen X, Cao W, Shi Y. Plasticity of mesenchymal stem cells in immunomodulation: pathological and therapeutic implications. Nat Immunol. 2014;15:1009-16.

38. Gieseke F, Bohringer J, Bussolari R, Dominici M, Handgretinger R, Muller I. Human multipotent mesenchymal stromal cells use galectin-1 to inhibit immune effector cells. Blood. 2010;116:3770-9.

39. Souza BSF, da Silva KN, Silva DN, Rocha VPC, Paredes BD, Azevedo CM, et al. Galectin-3 knockdown impairs survival, migration, and immunomodulatory actions of mesenchymal stromal cells in a mouse model of Chagas disease cardiomyopathy. Stem Cells Int. 2017;2017:3282656.

40. Oo YH, Shetty S, Adams DH. The role of chemokines in the recruitment of lymphocytes to the liver. Dig Dis. 2010;28:31-44.

41. Wang L, Wang FS, Chang C, Gershwin ME. Breach of tolerance: primary biliary cirrhosis. Semin Liver Dis. 2014:34:297-317.

42. Burr SP, Dazzi F, Garden OA. Mesenchymal stromal cells and regulatory T cells: the yin and Yang of peripheral tolerance? Immunol Cell Biol. 2013;91:12-8.

43. Ren G, Zhang L, Zhao X, Xu G, Zhang Y, Roberts Al, et al. Mesenchymal stem cell-mediated immunosuppression occurs via concerted action of chemokines and nitric oxide. Cell Stem Cell. 2008;2:141-50.

44. Sioud M. New insights into mesenchymal stromal cell-mediated T-cell suppression through galectins. Scand J Immunol. 2011;73:79-84.

45. John S, Mishra R. Galectin-9: from cell biology to complex disease dynamics. J Biosci. 2016:41:507-34.

46. Rabinovich GA, Toscano MA. Turning 'sweet' on immunity: galectin-glycan interactions in immune tolerance and inflammation. Nat Rev Immunol. 2009;9:338-52.

47. Gieseke F, Kruchen A, Tzaribachev N, Bentzien F, Dominici M, Muller I. Proinflammatory stimuli induce galectin-9 in human mesenchymal stromal cells to suppress T-cell proliferation. Eur J Immunol. 2013;43:2741-9.

48. Ungerer C, Quade-Lyssy P, Radeke HH, Henschler R, Konigs C, Kohl U, et al. Galectin-9 is a suppressor of $T$ and $B$ cells and predicts the immune modulatory potential of mesenchymal stromal cell preparations. Stem Cells Dev. 2014;23:755-66.

49. Gnecchi M, Zhang Z, Ni A, Dzau VJ. Paracrine mechanisms in adult stem cell signaling and therapy. Circ Res. 2008;103:1204-19.

50. Ratajczak MZ, Kucia M, Jadczyk T, Greco NJ, Wojakowski W, Tendera M, et al, Pivotal role of paracrine effects in stem cell therapies in regenerative medicine: can we translate stem cell-secreted paracrine factors and microvesicles into better therapeutic strategies? Leukemia. 2012;26:1 166-73.

51. Duran JM, Makarewich CA, Sharp TE, Starosta T, Zhu F, Hoffman NE, et al. Bone-derived stem cells repair the heart after myocardial infarction through transdifferentiation and paracrine signaling mechanisms. Circ Res. 2013;113: 539-52.

52. Choi J, Selmi C, Leung PS, Kenny TP, Roskams T, Gershwin ME. Chemokine and chemokine receptors in autoimmunity: the case of primary biliary cholangitis. Expert Rev Clin Immunol. 2016;12:661-72.

53. Manousou P, Kolios G, Drygiannakis I, Koulentaki M, Pyrovolaki K, Voumvouraki A, et al. CXCR3 axis in patients with primary biliary cirrhosis: a possible novel mechanism of the effect of ursodeoxycholic acid. Clin Exp Immunol. 2013;172:9-15.
54. Oo YH, Banz V, Kavanagh D, Liaskou E, Withers DR, Humphreys E, et al. CXCR3-dependent recruitment and CCR6-mediated positioning of Th-17 cells in the inflamed liver. J Hepatol. 2012;57:1044-51.

55. Shimoda S, Harada K, Niiro H, Yoshizumi T, Soejima Y, Taketomi A, et al. Biliary epithelial cells and primary biliary cirrhosis: the role of liver-infiltrating mononuclear cells. Hepatology. 2008;47:958-65.

56. Platanias LC. Mechanisms of type--- and type-II-interferon-mediated signalling. Nat Rev Immunol. 2005;5:375-86.

\section{Ready to submit your research? Choose BMC and benefit from:}

- fast, convenient online submission

- thorough peer review by experienced researchers in your field

- rapid publication on acceptance

- support for research data, including large and complex data types

- gold Open Access which fosters wider collaboration and increased citations

- maximum visibility for your research: over $100 \mathrm{M}$ website views per year

At BMC, research is always in progress.

Learn more biomedcentral.com/submissions 